\title{
Spatial variation of reef fishes and the relative influence of biotic and abiotic habitat traits
}

lacopo Bertocci $i^{1,2^{*}}$ (D) I. Sousa-Pinto ${ }^{1,3}$ and P. Duarte ${ }^{1,4}$

\begin{abstract}
Patterns of distribution of reef fishes were examined across three spatial scales and related to habitat traits along $25 \mathrm{~km}$ of the northern Portuguese coast. Response variables included the multivariate assemblage structure, the total number of taxa and individuals, and the abundance of single groups categorized according to their preference for the benthic, proximo-benthic or pelagic environment, feeding and reproductive behaviour. Habitat traits included topographic elements (small and large 'drops' like cracks and crevices) and the extent of dominant morpho-functional types of macroalgae (kelp, large foliose, small erect, turf-forming filamentous, and encrusting). All fish responses were characterized by the largest variance at the smallest scale (among transects tens $m$ apart), followed by that among reefs (hundreds $\mathrm{m}$ to $1 \mathrm{~km}$ apart) and almost null variance among sites (some $\mathrm{km}$ apart). Small and large 'drops' of the substratum explained, respectively, considerable variation of assemblage structure and the total abundance of individuals, while the extent of bare rock influenced the richness of taxa and that of benthic fishes, fishes feeding on sessile invertebrates and fishes laying benthic eggs or having nesting behaviour. Combinations of abiotic and biotic structural attributes of reefs influenced proximo-benthic fishes, the predators of mobile animals and fishes releasing pelagic eggs. The here reported associations between patterns of distribution of reef fishes and habitat traits have implications for the design of future protection schemes suitable to guarantee the conservation of reef fish communities and of the processes responsible for their variation. Within the SLOSS (single-large vs. several-small) debate in the design of marine reserves, for example, effective protection to the studied reef fishes would be provided by a set of small reserves, rather than a single large which might be appropriate for fishes having wider home ranges.
\end{abstract}

Keywords: Biological trait, Distribution pattern, Fish assemblage, Northeastern Atlantic, Reef structure

\section{Background}

There is evidence that patterns of variation of natural populations and assemblages are more evident at some scales than others [1-4]. This characteristic is crucial for a number of basic and applied ecological issues, including the notion that, since different processes are likely to operate differently in space and time, the identification of relevant scales of variation is essential to propose and then test their potential explanatory models $[5,6]$. For example, such an identification may be important to

\footnotetext{
*Correspondence: iacopo.bertocci@szn.it

${ }^{1}$ CIIMAR/CIMAR, Centro Interdisciplinar de Investigação Marinha e Ambiental, Terminal de Cruzeiros do Porto de Leixões, Av. General Norton de Matos s/n, 4450-208 Matosinhos, Portugal

Full list of author information is available at the end of the article
}

assess and predict the effects of anthropogenic disturbances operating at a hierarchy of spatial scales [7] and to support decisions about the design and management of effective protected areas [8-10].

The spatial patterns of biodiversity in coastal marine, especially rocky intertidal and shallow subtidal, systems have been widely examined, although across a range of scales usually smaller compared to that of terrestrial studies [but see 3, 11-14]. However, most analyses have identified a common pattern of relevant small- (tens to hundreds of centimetres) to middle-scale (tens to hundreds of metres) variation across several organisms and habitats $[2-4,6,15,16]$, highlighting the general principle that small-scale processes may be as, if not more, important as large-scale processes in driving patterns of 
distribution, abundance and diversity of coastal assemblages. As a consequence, small-scale natural variability should not be considered a statistical inconvenience, but a key issue to address in order to increase ecological understanding [17].

Shallow subtidal rocky reefs provide essential and heterogeneous habitat for a large diversity of organisms, supporting some of the most productive communities in the world [18]. Physical and biological variables have been indicated as major direct or indirect drivers of the small-scale spatial variation described for various reef populations and assemblages [19-22]. Different rock types, changes in the biological coverage, including the dominance of habitat-forming algae and invertebrates, of the bottom, and topographic complexity can drastically affect patterns of distribution of organisms living in close association to the substratum [19, 23-25]. Larger-scale variation in the structure and dynamics of reef communities, instead, may depend on factors such as differences in wave exposure [26] or food and propagule supply [27, 28]. Reef-associated fish assemblages, in particular, vary in abundance and diversity in response to variability in environmental conditions over a range of scales [29-33]. These may include the variability of oceanographic conditions as driver of fish variation at spatial scales of hundreds of kilometres or more [34, 35], and the physical structure of the reef as driver of fish variation at scales from metres to some kilometres [36].

Several studies have examined the relationships between reef habitat traits and associated fish assemblages in tropical [37-41] and temperate [31, 33, 42-44] systems. The physical nature of the substratum [19], the relative availability of vertical, horizontal or gently sloping substratum [45] and the cover and physical structure of algal assemblages [30,44, 46, 47], possibly affecting the intensity of local biological processes such as predation [48-50], are among the main habitat traits documented to determine the structure of reef fish assemblages. This knowledge made the direction and strength of the relationships between fish assemblages and the reef habitat a criterion for the implementation of management strategies of fisheries and the design and assessment of the effectiveness of marine protected areas [30,31]. None of these objectives can be achieved by focusing on fish assemblages without taking into account their positive versus negative, direct versus indirect, more or less specialized association with relevant habitat traits. Moreover, most studies aimed at assessing the effectiveness of marine reserves are based on comparing one protected area with one or more adjacent non-protected areas, but such an approach can provide unreliable results if the variability of variables intended to indicate the success of the implemented protection is not properly taken into account [51, 52]. Reserve effects and their responsible processes can be correctly identified and predicted only through sampling and monitoring designs including adequate replication in space and/or time [53, 54]. As a direct consequence, the possibility to generalise such issues to not yet implemented circumstances critically depends on identifying patterns of distribution of fishes and the relative influence of a range of biological and abiotic traits in relatively unstudied and ecologically peculiar systems.

In this context, the Portuguese continental coast provides an ideal case-study due to the occurrence of several species at their southern or northern distributional range edges and the documentation of clear latitudinal shifts in patterns of distribution and abundance of a number of macroalgal, invertebrate and fish organisms [33, 5558]. The cooler northern region, in particular, appears as where kelps, once dominating the entire Portuguese coast, are now restricted $[33,59]$. This is likely due to the combination of the recent reduction of the intensity of upwelling events and warming, which could have cause a northward retraction and reduction of the environmental conditions suitable for kelp species, and the reduced grazing intensity in the northern compared to the southern regions $[56,57,60]$.

This study adopted a hierarchical sampling design to partition the spatial variability at three spatial scales (tens of metres, hundreds to 1000 metres, and kilometres) of reef fish assemblages from the northern Portuguese coast. Such variability was correlated to a range of potentially responsible abiotic and biological habitat traits. In addition to indentifying and comparing the relevant scales of variation in the fish assemblage structure, richness of identified taxa and total number of individuals, the study specifically tested the following hypotheses regarding the spatial patterns of different fish groups categorized according to several life-history traits [61]: (1) the distribution of fishes belonging to the benthic, proximo-benthic and pelagic spatial guild [62] would be characterized, respectively, by increasingly larger relevant scales of variation; (2) smaller scales of variation would be displayed by fishes with feeding habits focusing mostly on sessile invertebrates compared to omnivores (those feeding on available food, including organic debris) and active predators of animals with larger movement abilities [63]; (3) the relative greater importance of smaller versus larger spatial scales would vary between fishes having benthic eggs or nesting behaviour and fishes having pelagic eggs and larvae which disperse over long distances [64]; (4) according to such functional differences, variation in local abiotic (type of substrate and topographic heterogeneity) and biotic (type and extent of dominant algal beds) habitat traits would explain a 
relatively larger proportion of variation of fishes having living, feeding or reproductive habits relying on smallerscale processes. In general, by partitioning the examined fish assemblages into their component functional groups that exploit, for different purposes, different parts of the spatial domain, testing such hypotheses aimed at investigating how local selection is related to spatial patterns of distribution [65, 66]. Fishes living in open habitats would likely rely on defences based on large numbers spread over large areas [67, 68], while fishes associated with soft and rocky bottom habitat traits would likely rely on relatively smaller, but more heterogeneously distributed numbers $[62,69]$.

\section{Methods}

\section{Study area and sampling design}

The study area (Fig. 1) spanned about $25 \mathrm{~km}$ along the northern Portuguese coast, where numerous rocky reefs occur interspersed within the predominantly sandy bottom [60]. Within the whole study area, the sampling was conducted at each of three haphazardly selected sites (about $5 \mathrm{~km}$ long, some $\mathrm{km}$ apart), each one including five randomly chosen rocky reefs (hundreds of metres up to about $1 \mathrm{~km}$ apart, 5-12 $\mathrm{m}$ depth). The almost rectilinear coastline, oriented from north to south, made all reefs comparable in terms of exposure to prevailing waves and wind (Fig. 1). These reefs are not subjected to any implemented protection status and, to our knowledge, are equally exposed to local fishing, typically artisanal, activities.

At each reef, the number of all fishes was estimated by a SCUBA diver by means of visual census performed along five, randomly chosen, transects $(25 \mathrm{~m} \times 5 \mathrm{~m}$ belts, $20-50 \mathrm{~m}$ apart) $[36,70]$. Most fishes were identified to the species level, in some cases lumping different individuals to the same genus when poor water transparency did not allow to distinguish species in a fully consistent way. This was the case, for instance, of labrids of the genus Symphodus, especially when represented by juvenile individuals. The level of identification of each fish taxon, however, was the same for all sampled transects and reefs. The number of large $(>1 \mathrm{~m})$ and small $(<1 \mathrm{~m})$ topographic elements (hereafter indicated as large and small 'drops', including cracks, crevices, caves and holes) of the substratum was also counted within each $125 \mathrm{~m}^{2}$ transect used for the fish counts [71]. Finally, a second diver measured, along each transect, the relative extent of the portions which were characterised by different types of substratum (continuous rock, large boulders, cobbles/pebbles, sand) and dominated by different morpho-functional groups of algae, including kelp (e.g., Laminaria hyperborea and Sacchoriza polyschides), small erect (e.g., Corallina officinalis), large foliose (e.g.,
Dyctiota dichotoma), turf-forming filamentous (e.g., Polysiphonia spp.) and encrusting algae (e.g., Lithophyllum incrustans), plus bare rock.

The study was carried out, by the same two divers, between September 2010 and July 2012. During this period, safe and effective diving opportunities were critically constrained by the harsh weather and sea conditions characterizing the study area [72], making the sampling occasions rather opportunistic. Such a logistic difficulty prevented to formally test any time-related hypothesis. However, each set of five reefs within each site was sampled over a period of about 1.5 years and guaranteeing that at least two reefs were sampled in each of the 'cool' and the 'warm' period (December-May and June-November, respectively) of sea water in the region [73]. This allowed to keep the temporal variability of the sampling of each set of five reefs as much as possible comparable among sites, thus reducing, though not completely removing, the potential confounding between the specifically examined spatial variation and the not fully controlled temporal variation. In addition, the sampling was always done during the day and avoiding crepuscular periods.

\section{Data analyses}

Spatial patterns in the structure of whole fish assemblages were examined by a two-way permutational multivariate analysis of variance (PERMANOVA) [74], with 'Reef' nested in 'Site' and the five transects sampled in each reef providing the replicates. This analysis was based on Bray-Curtis dissimilarities calculated from square root-transformed data. The same model of analysis was used in analysis of variance (ANOVA) to examine variation in the total number of identified taxa (a surrogate measure for species richness), the total number of fish individuals and the abundance of each functional group of fishes. Before each ANOVA, homogeneity of variances was assessed with Cochran's $C$ test and data were transformed when necessary to remove heterogeneity and avoid increased probability of type I error.

To quantify and compare the spatial variability of univariate and multivariate response variables at each sampled scale (among transects, reefs and sites), variance components were calculated from ANOVA (as well as pseudo-variance components from PERMANOVA) [30] by equating empirical and expected mean squares [75, 76]. Obtained negative estimates of variance were interpreted as sample underestimates of very small to null variances and set to zero [76, 77]. All variance components were calculated from untransformed data [e.g., 78] and the contribution of each scale was finally expressed as the percentage to the total variance of each multivariate and univariate response variable. 


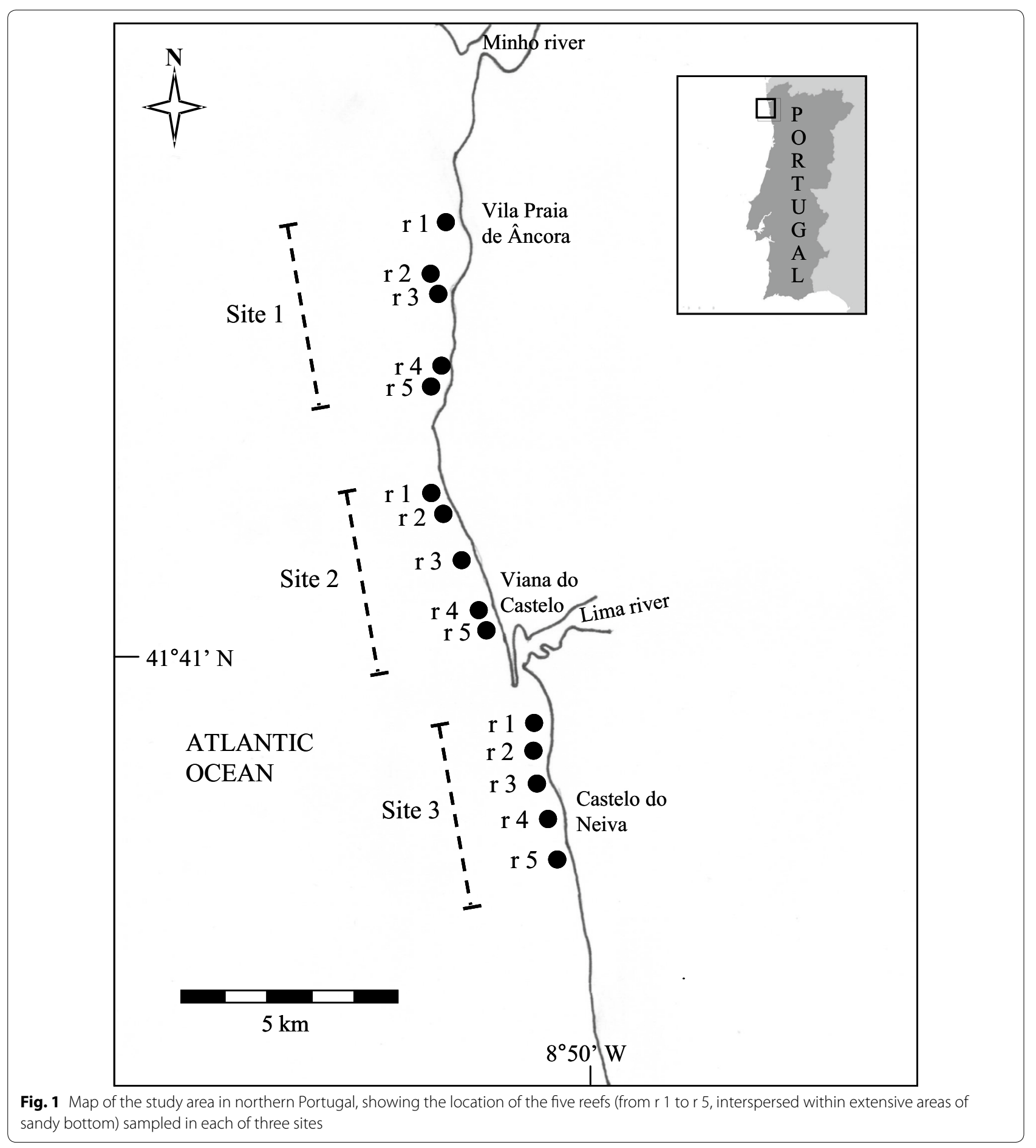

The distance-based linear modelling (DISTLM) [79] routine was used to run multiple regression models to assess the contribution of each abiotic (small vs. large 'drops' and four types of substratum) and biotic (five groups of dominant algae and bare rock) habitat traits to the total variation of each response variable. Model selection was performed by first calculating second order Akaike information criterion values $\left(\mathrm{AIC}_{\mathrm{C}}\right)$, which are more appropriate than raw AIC values when, such as in the present case, the number of observations is relatively small compared to the number of parameters in the model [80-82]. Then, for each model, the differences 
in $\mathrm{AIC}_{\mathrm{C}}$ with respect to the $\mathrm{AIC}_{\mathrm{C}}$ of the best candidate model were computed. Finally, second order Akaike weights were calculated as described in [80-82].

\section{Results}

\section{Structure, richness and overall abundance of reef fish} assemblage

A total of 22 fish taxa were identified during the study, with about $90 \%$ of the total number of individuals provided by eight most common taxa (Additional file 1: Supplementary material and Fig. 2). The structure of the whole assemblage varied significantly among reefs, although the smallest scale (among transects) provided the greatest contribution to the total (pseudo) variance. This was about six times and seventy-seven times greater than that of the reef and the site scale, respectively (Table 1 and Fig. 3a). Both the richness of taxa and the total number of individuals showed patterns of spatial variation very similar to those of the whole assemblage, with the former variable, in particular, being characterized by a null variance at the scale of sites (Table 1 , Fig. 3b, c).

\section{Functional groups of reef fishes}

Analogously, spatial patterns of each functional group of fishes showed the greatest variance at the transect scale, followed by the reef and the site scales (Fig. $3 d-j$ ). The largest examined scale provided a null contribution to the variance of the benthic guild (Fig. 3d), the omnivores (Fig. 3f), the browsers of benthic invertebrates (Fig. 3g),

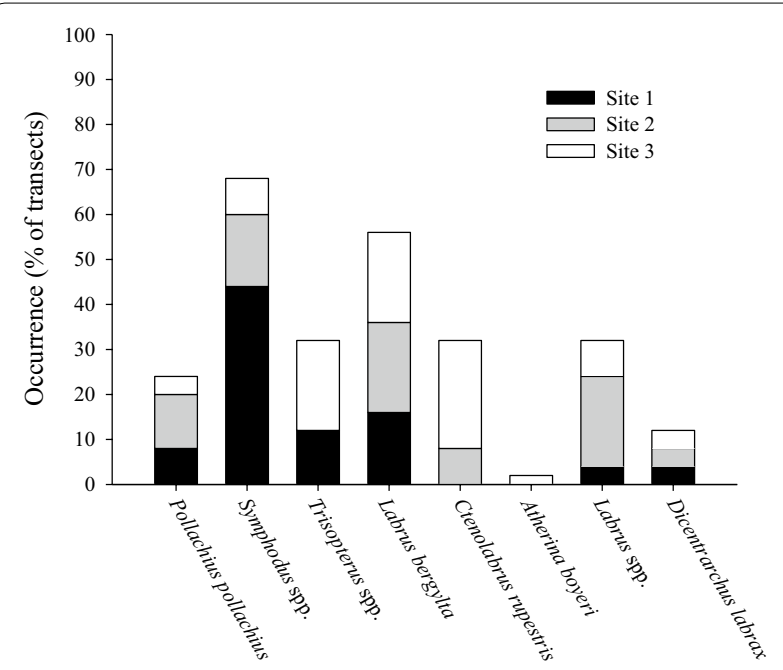

Fig. 2 Occurrence (proportion of transects where a fish taxon was found, out of the total number of sampled transects) of the eight most numerous fish species or genera observed during the study at each sampled site. The reported fish taxa are those collectively exceeding $90 \%$ of the total number of individuals sampled throughout the study and both the fishes laying benthic eggs, or showing a nesting behaviour (Fig. 3i), and pelagic eggs (Fig. 3j). The browsers of benthic invertebrates and fishes deploying benthic eggs were also the only response variables for which the contribution of the among-reefs variance reached at least $50 \%$ of that provided by the transect scale (Fig. $3 g$, i, respectively). A significant variation among reefs, however, was found only for the browsers of benthic invertebrates and the omnivorous fishes (Table 1), although such effect might have been, to some extent, actually masked by the larger smaller-scale variability of all examined responses.

The planktivore and the pelagic group included, respectively, only the 'big-scale sand smelt', Atherina boyeri (15 individuals), and the 'horse mackerel', Trachurus sp. (one individual), which were all found along a single transect of one reef at site 3 . Therefore, these two groups were not analysed individually.

\section{Influence of habitat traits on reef fishes}

The 'best' model explaining patterns of variation of the whole fish assemblage structure included only the small 'drops' as a relevant habitat trait (Table 2). This habitat variable provided a small, but significant, contribution to variation of the assemblage structure. The availability of bare rock and the number of large 'drops', instead, were included into the best model regarding the richness of fish taxa and the total number of fish individuals, respectively (Table 2). Both habitat traits were significantly related to the corresponding fish variable (Table 3).

Concerning individual fish groups, bare rock was also the only habitat variable included in the best model explaining variation of the benthic fishes, the browsers of benthic invertebrates and the fishes laying benthic eggs/ having nesting behaviour (Table 2), although its influence was significant for the last two groups only (Table 3 ). The same set of four variables (large and small 'drops', extent of turf-formers as dominant algae, and bare rock) was selected by the best model explaining the variation of the proximo-benthic fishes and of the predators of mobile animals (Table 2), with a cumulative contribution of 20.6 and $23.5 \%$, respectively (Table 3 ). A significant influence, however, was found only for the number of large drops on both such response variables and for the number of small topographic elements on active predators (Table 3). The variation of the abundance of omnivorous fishes was best explained by the model including only the large foliose algae (Table 2), though the influence of this habitat variable was not significant (Table 3). Finally, the variation of the abundance of fishes releasing pelagic eggs was best explained by the model including foliose algae and sandy bottom as the main available habitats (Table 2). Such habitat variables were both significant and provided 
Table 1 Results of multivariate (PERMANOVA on assemblage structure) and univariate (ANOVA on all other variables) analyses testing for the effects of 'sites' and 'reefs' on several response variables of fish assemblages

\begin{tabular}{|c|c|c|c|c|c|c|}
\hline Source of variation & $d f$ & MS & $F$ & $\mathbf{p}$ & Denominator & $\%$ of total variance \\
\hline \multicolumn{7}{|l|}{ Assemblage structure ${ }^{a}$} \\
\hline Site & 2 & 8553.6 & $1.18^{d}$ & 0.209 & Reef (site) & 1.1 \\
\hline Reef (site) & 12 & 7227.0 & $1.82^{\mathrm{d}}$ & 0.001 & Residual & 14.0 \\
\hline Residual & 60 & 3966.6 & & & & 84.9 \\
\hline \multicolumn{7}{|l|}{ Total \# of fish taxa ${ }^{a}$} \\
\hline Site & 2 & 0.115 & 0.52 & 0.609 & Reef (site) & 0 \\
\hline Reef (site) & 12 & 0.223 & 2.02 & 0.037 & Residual & 19.2 \\
\hline Residual & 60 & 0.110 & & & & 80.8 \\
\hline \multicolumn{7}{|c|}{ Total \# of fish individuals ${ }^{b}$} \\
\hline Site & 2 & 0.533 & 0.38 & 0.563 & Reef (site) & 1.0 \\
\hline Reef (site) & 12 & 1.400 & 2.05 & 0.024 & Residual & 14.3 \\
\hline Residual & 60 & 0.684 & & & & 84.7 \\
\hline \multicolumn{7}{|l|}{ Spatial guild: benthic ${ }^{b}$} \\
\hline Site & 2 & 0.002 & 0.00 & 0.997 & Reef (site) & 0 \\
\hline Reef (site) & 12 & 0.620 & 1.74 & 0.080 & Residual & 19.3 \\
\hline Residual & 60 & 0.355 & & & & 80.7 \\
\hline \multicolumn{7}{|c|}{ Spatial guild: proximo-benthic ${ }^{c}$} \\
\hline Site & 2 & 60.093 & 2.12 & 0.163 & Reef (site) & 6.5 \\
\hline Reef (site) & 12 & 28.400 & 1.83 & 0.064 & Residual & 13.3 \\
\hline Residual & 60 & 15.547 & & & & 80.2 \\
\hline \multicolumn{7}{|l|}{ Diet: omnivorous ${ }^{c}$} \\
\hline Site & 2 & 0.040 & 0.14 & 0.871 & Reef (site) & 0 \\
\hline Reef (site) & 12 & 0.287 & 2.05 & 0.035 & Residual & 17.3 \\
\hline Residual & 60 & 0.140 & & & & 82.7 \\
\hline \multicolumn{7}{|c|}{ Diet: browser of benthic invertebrates ${ }^{b}$} \\
\hline Site & 2 & 0.027 & 0.02 & 0.976 & Reef (site) & 0 \\
\hline Reef (site) & 12 & 1.113 & 3.07 & 0.002 & Residual & 34.0 \\
\hline Residual & 60 & 0.363 & & & & 66.0 \\
\hline \multicolumn{7}{|c|}{ Diet: predator of mobile animals ${ }^{c}$} \\
\hline Site & 2 & 67.080 & 2.72 & 0.106 & Reef (site) & 9.2 \\
\hline Reef (site) & 12 & 24.660 & 1.66 & 0.099 & Residual & 10.6 \\
\hline Residual & 60 & 14.853 & & & & 80.2 \\
\hline \multicolumn{7}{|l|}{ Eggs type: benthic ${ }^{b}$} \\
\hline Site & 2 & 0.063 & 0.05 & 0.948 & Reef (site) & 0 \\
\hline Reef (site) & 12 & 1.165 & 3.10 & 0.002 & Residual & 37.5 \\
\hline Residual & 60 & 0.376 & & & & 62.5 \\
\hline \multicolumn{7}{|l|}{ Eggs type: pelagic ${ }^{c}$} \\
\hline Site & 2 & 2.218 & 1.17 & 0.485 & Residual $^{e}$ & 0 \\
\hline Reef (site) & 12 & 2.164 & 1.14 & 0.347 & Residual & 5.2 \\
\hline Residual & 60 & 1.895 & & & & 94.8 \\
\hline
\end{tabular}

Significant effects are reported in bold. The \% contribution of the variance component calculated at each spatial scale to the total variance is reported in the last column

$\mathrm{a}, \mathrm{b}, \mathrm{c}$ Analysis done on square root-transformed, $\log (\mathrm{x}+1)$ transformed or untransformed data, respectively

d Pseudo- $F$ value calculated through permutations

e Residual MS used as denominator for the Site test after elimination of the reef (site) term that was not significant at $p>0.25$ [76] 


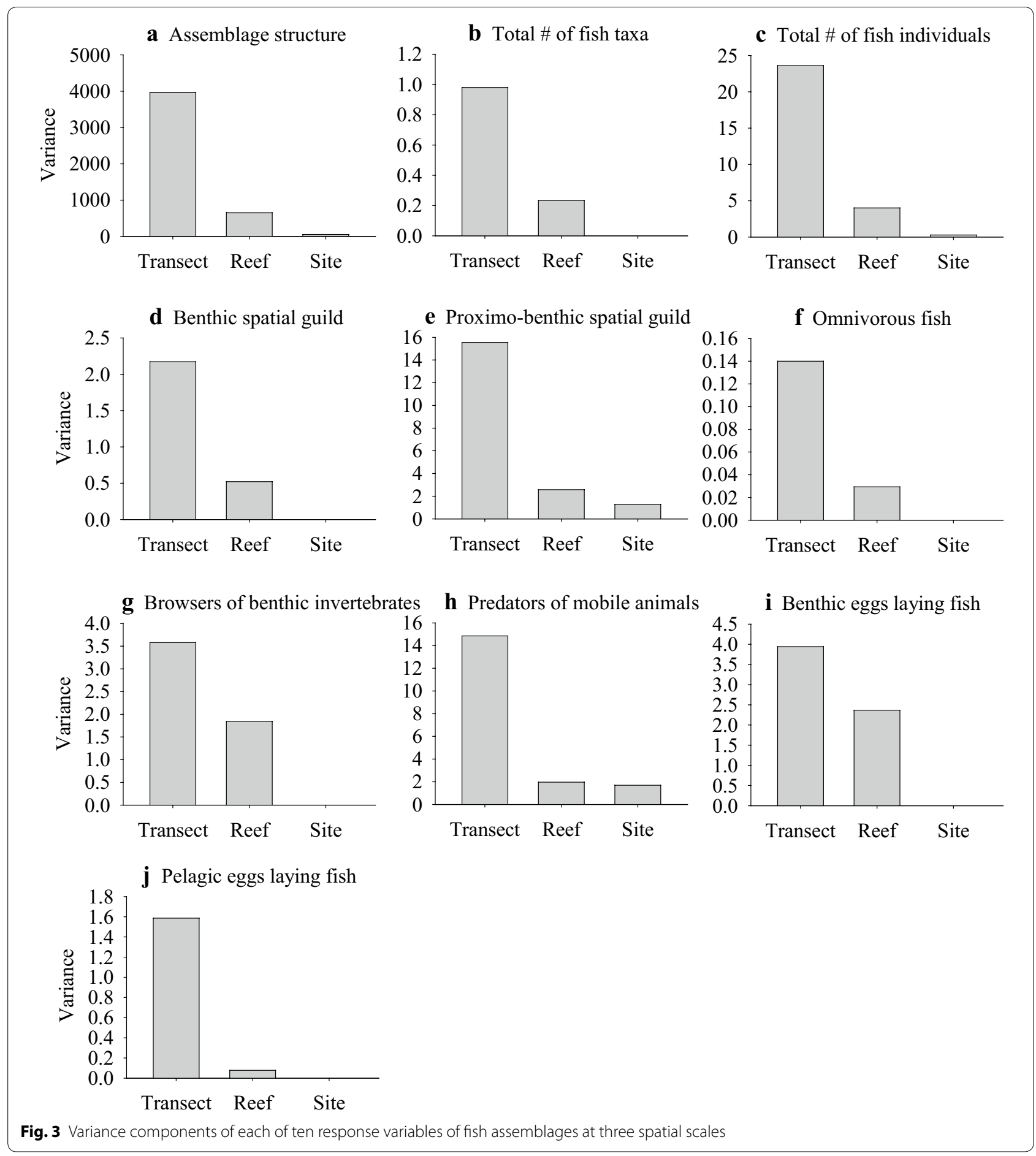

a cumulative contribution of $25.5 \%$ to the total variation of pelagic spawners (Table 3 ).

\section{Discussion}

The most evident finding of this study is the far larger variance of reef fish distribution at the transect compared to the larger scales. Such pattern was observed consistently across all examined response variables, although a significant among-reefs variability was also documented for the structure and aggregate measures of richness and abundance (total number of taxa and total number of individuals) of the whole assemblage and for the abundance of both fish groups having omnivorous or browser benthic invertebrates feeding habit. 
Table 2 Results of $\mathrm{AIC}_{\mathrm{c}}$ analysis for competing models assessing the abiotic (sd small 'drops', Id large 'drops', br bare rock, $c r$ continuous rock, $p c$ pebbles/cobbles, $s$ sand) and biotic (en encrusting algae, er erect algae, $f$ foliose algae, $k$ kelp, $t$ turf) habitat variables (no. var. number of habitat variables for the model) to the variation of different response variables of fish assemblages

\begin{tabular}{|c|c|c|c|c|}
\hline No. var. & Variables & $\mathrm{AIC}_{\mathrm{C} i}$ & $\Delta_{i}\left(\mathrm{AIC}_{\mathrm{C}}\right)$ & $w_{i}\left(\mathrm{AIC}_{\mathrm{C}}\right)$ \\
\hline \multicolumn{5}{|c|}{ Assemblage structure } \\
\hline 1 & $\mathrm{sd}$ & 634.8 & 0 & 0.260 \\
\hline 2 & $k+s d$ & 635.1 & 0.3 & 0.224 \\
\hline 3 & $k+s d+l d$ & 635.4 & 0.6 & 0.193 \\
\hline 4 & $k+s+s d+l d$ & 636.1 & 1.3 & 0.136 \\
\hline 5 & $k+p c+s+s d+l d$ & 637.0 & 2.2 & 0.087 \\
\hline \multicolumn{5}{|c|}{ Total \# of fish taxa } \\
\hline 1 & $\mathrm{br}$ & 9.4 & 0 & 0.387 \\
\hline 2 & $b r+l d$ & 9.8 & 0.3 & 0.333 \\
\hline 3 & $k+b r+l d$ & 11.1 & 1.7 & 0.165 \\
\hline 4 & $f+k+b r+l d$ & 12.9 & 3.4 & 0.071 \\
\hline 5 & $f+k+t+b r+l d$ & 14.8 & 5.3 & 0.027 \\
\hline \multicolumn{5}{|c|}{ Total \# of fish individuals } \\
\hline 1 & ld & 240.5 & 0 & 0.371 \\
\hline 2 & $b r+l d$ & 241.4 & 0.8 & 0.248 \\
\hline 3 & $b r+s d+l d$ & 242.4 & 1.8 & 0.151 \\
\hline 4 & $t+b r+s d+l d$ & 242.4 & 1.9 & 0.144 \\
\hline 5 & $k+t+b r+s d+l d$ & 244.4 & 3.8 & 0.056 \\
\hline \multicolumn{5}{|c|}{ Benthic spatial guild } \\
\hline 1 & $\mathrm{br}$ & 133.9 & 0 & 0.577 \\
\hline 2 & $\mathrm{er}+\mathrm{br}$ & 135.5 & 1.6 & 0.259 \\
\hline 3 & $e r+b r+p c$ & 137.3 & 3.4 & 0.106 \\
\hline 4 & $e r+t+b r+p c$ & 139.3 & 5.4 & 0.039 \\
\hline 5 & $e r+k+t+b r+p c$ & 141.4 & 7.5 & 0.014 \\
\hline \multicolumn{5}{|c|}{ Proximo-benthic spatial guild } \\
\hline 4 & $t+b r+s d+l d$ & 212.4 & 0 & 0.319 \\
\hline 3 & $t+s d+l d$ & 213.3 & 0.8 & 0.214 \\
\hline 5 & $k+t+b r+s d+l d$ & 213.6 & 1.2 & 0.175 \\
\hline 2 & $s d+l d$ & 214.8 & 2.4 & 0.096 \\
\hline 6 & $k+t+b r+c r+s d+l d$ & 214.8 & 2.4 & 0.096 \\
\hline \multicolumn{5}{|c|}{ Omnivorous fishes } \\
\hline 1 & f & -135.2 & 0 & 0.433 \\
\hline 2 & $f+b r$ & -134.6 & 0.7 & 0.305 \\
\hline 3 & $f+k+b r$ & -133.2 & 2.0 & 0.159 \\
\hline 4 & $e r+f+k+b r$ & -131.4 & 3.8 & 0.065 \\
\hline 5 & $e r+f+k+b r+l d$ & -129.5 & 5.7 & 0.025 \\
\hline \multicolumn{5}{|c|}{ Browsers of benthic invertebrates } \\
\hline 1 & $\mathrm{br}$ & 122.7 & 0 & 0.561 \\
\hline 2 & $\mathrm{er}+\mathrm{br}$ & 124.3 & 1.5 & 0.265 \\
\hline 3 & $e r+t+b r$ & 126.1 & 3.3 & 0.108 \\
\hline 4 & $e r+t+b r+p c$ & 127.9 & 5.2 & 0.042 \\
\hline 5 & $e r+k+t+b r+p c$ & 129.8 & 7.1 & 0.016 \\
\hline \multicolumn{5}{|c|}{ Predators of mobile animals } \\
\hline 4 & $t+b r+s d+l d$ & 205.6 & 0 & 0.311 \\
\hline
\end{tabular}

Table 2 continued

\begin{tabular}{cllll}
\hline No. var. & Variables & AIC $_{\mathbf{C}_{i}}$ & $\boldsymbol{\Delta}_{\boldsymbol{i}}\left(\mathbf{A I C}_{\mathbf{C}}\right)$ & $\boldsymbol{w}_{\boldsymbol{i}}\left(\mathbf{A I C _ { \mathbf { C } }}\right)$ \\
\hline 3 & $\mathrm{br}+\mathrm{sd}+\mathrm{ld}$ & 206.0 & 0.4 & 0.255 \\
5 & $\mathrm{k}+\mathrm{t}+\mathrm{br}+\mathrm{sd}+\mathrm{ld}$ & 206.8 & 1.2 & 0.171 \\
6 & $\mathrm{k}+\mathrm{t}+\mathrm{br}+\mathrm{cr}+\mathrm{sd}+\mathrm{ld}$ & 208.0 & 2.4 & 0.094 \\
2 & $\mathrm{~s} d+\mathrm{ld}$ & 208.2 & 2.6 & 0.085 \\
Fishes laying benthic eggs & & & \\
1 & $\mathrm{br}$ & 133.9 & 0 & 0.577 \\
2 & $\mathrm{er}+\mathrm{br}$ & 135.5 & 1.6 & 0.259 \\
3 & $\mathrm{er}+\mathrm{br}+\mathrm{pc}$ & 137.3 & 3.4 & 0.106 \\
4 & $\mathrm{er}+\mathrm{t}+\mathrm{br}+\mathrm{pc}$ & 139.3 & 5.4 & 0.039 \\
5 & $\mathrm{er}+\mathrm{k}+\mathrm{t}+\mathrm{br}+\mathrm{pc}$ & 141.4 & 7.5 & 0.014 \\
Fishes laying pelagic eggs & & & \\
2 & $\mathrm{f}+\mathrm{s}$ & 19.6 & 0 & 0.440 \\
3 & $\mathrm{f}+\mathrm{k}+\mathrm{s}$ & 20.4 & 0.8 & 0.295 \\
4 & $\mathrm{f}+\mathrm{en}+\mathrm{k}+\mathrm{s}$ & 21.8 & 2.2 & 0.147 \\
5 & $\mathrm{f}+\mathrm{en}+\mathrm{k}+\mathrm{s}+\mathrm{sd}$ & 23.3 & 3.8 & 0.066 \\
6 & $\mathrm{f}+\mathrm{en}+\mathrm{k}+\mathrm{s}+\mathrm{sd}+\mathrm{ld}$ & 25.4 & 5.8 & 0.024 \\
\hline
\end{tabular}

$\Delta_{i}\left(\mathrm{AIC}_{\mathrm{C}}\right)=\left[\mathrm{AIC}_{\mathrm{Ci}}-\min \left(\mathrm{AIC}_{\mathrm{C}}\right)\right] \cdot w_{i}\left(\mathrm{AlC}_{\mathrm{C}}\right)=\exp \left[-0.5 \Delta_{i}\left(\mathrm{AIC}_{\mathrm{C}}\right)\right] / \Sigma_{k=1, K}$

$\exp \left[-0.5 \Delta_{k}\left(A \mid C_{C}\right)\right]$. The number of observations entering into the calculation of $\mathrm{AlC}_{\mathrm{C}}$ is 75

Heterogeneity at small scale (tens of metres) is increasingly emerging as an ubiquitous feature of reef fishes. It was documented in the last decades by studies, in most cases even encompassing a larger extent and more numerous scales than the present one, in New Zealand [30, see also 83 for a review], Australia [29, 37, 39, 71], Aleutian Archipelago [84], Mexican Caribbean coast [85] and the Mediterranean Sea [31, 86]. This can be explained considering that several tropical [87-89] and temperate $[45,90-92]$ reef fish species show home ranges that, though changing over their life-cycles, are within a few thousand $\mathrm{m}^{2}$ or even confined to less than $10 \mathrm{~m}^{2}$.

Spatial variation at the scale of tens of metres can be driven by variation in habitat structure [31, 42, 71, 84] and its possible interaction with recruitment [93] and post-recruitment [94] processes. In this respect, the present finding identifying small or large drops as explaining spatial variation of the whole structure and overall abundance of fish assemblages is consistent with their expected role in increasing the number and diversity of microhabitats. These may be associated to a greater small-scale heterogeneity in the distribution of reef fishes $[31,45,71,84,85]$. In principle, a larger availability of microhabitats might also allow relatively more species to coexist in the same area [e.g., 86], but both small and large drops, as well as each dominant algal group, did not explain variation of the total number of taxa. This variable, however, was influenced by the availability of bare rock, potentially providing indirect support to analogous considerations. In fact, the whole set of sampled 


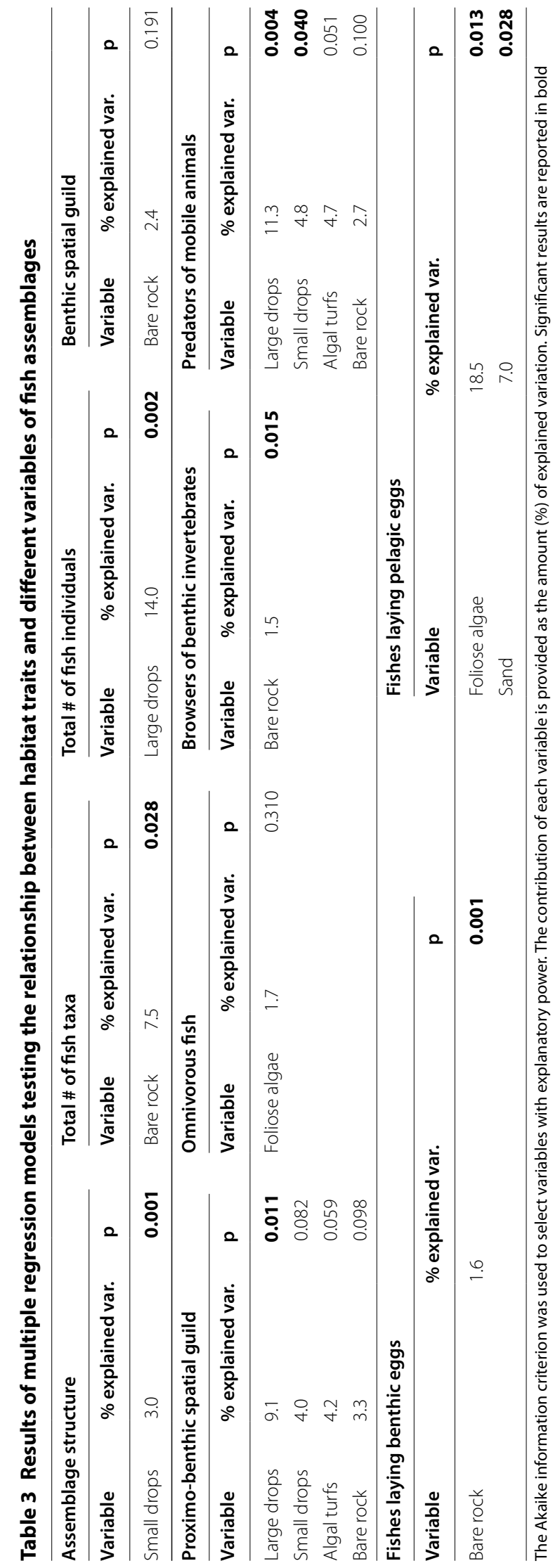


transects was almost evenly divided into those showing bare rock as the dominant habitat along more than $5 \%$ of the $25 \mathrm{~m}$ extent, and those where bare rock was less available or completely absent (36 and 39 transects, respectively). On average, a single taxon characterized the first circumstance, while such number was almost doubled in the second one. Of course, such small absolute numbers might just depend on chance rather than any specific ecological mechanism, thus suggesting caution in attempting to generalise ecological mechanisms possibly responsible for spatial patterns of richness of reef fishes. However, they could provide further support to the general importance of habitat heterogeneity in the present system.

Adding to the small-scale variation, previous investigations have detected a considerable proportion of variance in the distribution of reef fishes at scales comparable to that of the present sites. This was often explained with spatial changes of hydrodynamics [95], the relative availability of algae playing different functional roles [30, 84, $96,97]$, or a combination of biotic and abiotic processes [32, 98, 99]. Such differences, instead, were unlikely to occur in the present system, where all sampled reefs and sites were chosen as being comparable in terms of wave exposure and general occurrence of macroalgal beds and might have critically contributed to the smaller variation at these scales compared to the transect scale. The only response variables showing a considerable proportion of variance at the reef scale were the abundance of fishes feeding mostly on sessile invertebrates and that of fishes generally having a nesting behaviour. Both life-traits may imply patterns of variation consistent with those of factors and processes affecting the availability of suitable food or protection from predators and harsh environmental conditions. For example, Tuya et al. [44] described relevant variation in the abundance of labrid fishes (the numerically dominant taxon in the present study, collectively providing about $42 \%$ of all sampled individuals) as a positive function of among-reefs variation of physical (rock topography) and biotic (cover of red algae) habitat traits. Heterogeneous habitats may facilitate the access to invertebrate preys, at the same time providing enough shelter and protection from predators. Here, the same variables were not found to explain any amount of variation of such fish groups, but the influence of bare rock might suggest, once again, analogous underlying mechanisms. In fact, the three sampled reefs where the browsers of sessile invertebrates and the nesting fishes were more abundant (respectively, 17 and 18 individuals averaged over reef 4 at site 1 , reef 4 at site 2 and reef 2 at site 3) were characterized by a proportion of bare rock as dominant habitat about three times lower (10.9 vs. $31.3 \%)$ than that of the three reefs where they were less abundant (in both cases, $<1$ individual averaged across reef 3 at site 1 and reefs 3 and 4 at site 3 ).

Contrarily to the initial hypothesis predicting different relevant scales of variation for fish groups with different spatial use of the habitat, an increasingly smaller variance at increasing scale was quantified for all fish groups. Our expectation was based on the role of factors, such as high mobility and long-distance feeding and reproductive behaviour, as direct drivers of patterns of fish distribution. Although this type of relationship can not be unambiguously ruled out by the present findings, the influence of factors potentially determining relevant variation of some fish groups at relatively large scale might be secondary compared to that of complex interactions with within-reef processes. This could occur, in particular, in the present system, where isolated rocky reefs occur interspersed within extensive portions of sandy bottom. Under such circumstances, even species whose life-traits would make minimal small-scale variation expectable might find conditions that are critical for aspects of their life history near or within rocky reefs and not on the surrounding sandy bottom. This could be the case, for example, of the here common 'European sea bass', Dicentrarchus labrax, which has high mobility and releases pelagic eggs [61], but may depend on within-reef occurring spawning grounds [100]. In a system, such as the present one, lacking marked among-sites differences in potentially relevant factors, including wave exposure [95], position relatively to the coast [101] and fishing pressure [102], smaller-scale variation might logically predominate irrespectively of fish life-histories relying on obvious local or larger-scale processes. Nonetheless, the general lack of among-sites significant variation should be interpreted with caution since the present impossibility to tease apart spatial and temporal variation likely increased the among-reefs variation, potentially masking, at least in part, among-sites differences. It is worth noting, however, that the Site test remained non-significant also when the non-significant Reef source of variation was eliminated from the analyzed model (e.g., ANOVA on fishes deploying pelagic eggs), suggesting that such spatial homogeneity was due to an actual ecological feature rather than biased by sampling constraints.

Finally, a note of caution is needed when interpreting present findings only in terms of spatial patterns of variation and their possible underlying processes, since logistic difficulties eventually led to a sampling design where the estimated patterns of spatial variance were, at least in part, likely affected by temporal variance. The availability, within each site, of replicate reefs sampled in both the 'cool' and the 'warm' period reported for the study region [73] allowed to reduce, but not to fully remove, such a confounding effect. Indeed, reef-associated fish 
assemblages may respond to environmental conditions with changes in abundance not just at different spatial scales, but also at a range of temporal scales [29-32]. For instance, oceanographic differences can drive seasonal patterns of fish recruitment differing between adjacent islands within the same archipelago [102]. There is evidence, however, that temporal variation of adult reef fishes is much smaller than spatial variation, at least on scales ranging from days and weeks to months, and as long as crepuscular periods are avoided [103, 104]. In spite of the mentioned limitations, the present discussion on spatial patterns of the studied fish assemblages is built on the notion that variability in space (from metres to tens up to $100 \mathrm{~km}$ ) is often more important than variability in time (weeks to months and even years), especially when response variables are examined at the assemblage level [29, 30, 32, 37, 71].

\section{Conclusion}

Although this study did not address any issue specifically related to marine protected areas, it provides basic ecological knowledge that is relevant for the management and conservation of reef fishes. The identification of relevant scales of variation of natural populations and assemblages is essential to design protection schemes suitable to guarantee the protection of their responsible processes $[10,31]$. The implementation of local strategies intended to conserve reef fish assemblages, for instance, is likely to fail if their patterns of distribution, abundance and diversity are mainly shaped by larger-scale (e.g., regional) drivers. This kind of problem was highlighted by Benedetti-Cecchi et al. [8] who did not find clear evidence of realized protection on algal and invertebrate assemblages of shallow Mediterranean rocky coasts, likely due to the fact that the relevant scales of variation were not properly represented within the established protected area. At the same time, multi-scale sampling designs able to quantify and compare the scales of variation of ecological variables of interest are required to assess the positive or negative impacts of existing human activities, including already implemented protected areas and fishing [99].

The northern Portuguese coast, in particular, is subjected to small-scale fishing using artisanal gears [105] that may negatively impact reef fishes and habitats more than it is normally assumed [106]. Therefore, the present findings are crucial firstly to assess whether such anthropogenic activities have the potential to alter the relevant scales of variation of reef fishes through interfering with their likely responsible processes, secondly to optimise the design of planned protection schemes. In the context of the well-known SLOSS dichotomy (a single-large vs. several-small options debated in reserve design since the 1970s) [see 107], effective protection to the studied reef fishes might be provided by a set of small reserves, likely preserving the important processes, rather than a single large one, which might be more appropriate for fishes having wide home ranges [e.g., 108]. Interestingly, the same conclusion was drawn by Hattori and Shibuno [109] examining reefs lacking, analogously to the present ones, territorial herbivore fishes. Moreover, present data may help to design monitoring programmes specifically focusing on the relevant spatial scales, thus improving their cost-benefit analysis in logistically challenging systems in terms of sampling conditions.

In conclusion, although further investigations, including experimental manipulations of habitat traits and specific observations of fish behaviour, competition and predation, are needed to unambiguously reveal causeeffect relationships, this study contributes to disclose the multi-scale drivers of the structure of reef fishes in a relatively unstudied region. This is a key goal of fish ecologists and provides fundamental information for the management and conservation of a coastal system hosting fishery- and ecologically important species and habitats. Moreover, present data may provide a reference for future comparisons aimed at assessing the possibility to generalize the same patterns to larger scales and systems.

\section{Additional file}

Additional file 1. List of fish species or higher taxa observed during the study, classified according to their spatial guild (B, benthic; PB, Proximo-benthic; $\mathrm{P}$, pelagic), Diet $(\mathrm{O}, \mathrm{Omnivorous;} \mathrm{Bi}$, Browsers of benthic invertebrates; Pm, Active predators of mobile animals; Pk, Planktivorous), and type of eggs (B, benthic; $P$, Pelagic).

\section{Abbreviations}

ANOVA: analysis of variance; DISTLM: distance-based linear modelling; PERMANOVA: permutational multivariate analysis of variance; SLOSS: single large versus several small.

\section{Authors' contributions}

$\mathrm{IB}$ and PD conceived and designed the study and collected and analysed the data; IB analysed the data and led the writing of the manuscript; PD and ISP assisted with the writing of the manuscript; all authors read and approved the final manuscript.

\section{Author details}

${ }^{1}$ CIIMAR/CIMAR, Centro Interdisciplinar de Investigação Marinha e Ambiental, Terminal de Cruzeiros do Porto de Leixões, Av. General Norton de Matos s/n, 4450-208 Matosinhos, Portugal. ${ }^{2}$ Stazione Zoologica Anton Dohrn, Villa Comunale, 80121 Naples, Italy. ${ }^{3}$ Department of Biology, Faculty of Sciences, University of Porto, Rua do Campo Alegre s/n, 4169-007 Porto, Portugal. ${ }^{4}$ Norwegian Polar Institute, Fram Centre, Post box 6606, Langnes, 9296 Tromsø, Norway.

\section{Acknowledgements}

We thank 'Cavaleiros do Mar'for technical support during diving operations, L. Magina, S. Biskup and F. Arenas for help with fieldwork, and L. Maiorano for discussions on the statistical analyses.

Competing interests

The authors declare that they have no competing interests. 


\section{Availability of data and materials}

The datasets used and/or analysed during the current study are available from the corresponding author on reasonable request.

\section{Ethics approval and consent to participate}

The study did not involve any destructive sampling and was carried out in accomplishment of all the pertinent Portuguese laws.

\section{Funding}

This study was funded by Polis Litoral Norte S.A. through the project 'Estudo de caracterização da actividade pesqueira costeira e dos seus impactes nos recursos e nas comunidades marinhas do Litoral Norte' (241/10/PC09 Grant) and by the European Regional Development Fund (ERDF) through the POFCCOMPETE, QREN, and the Portuguese Foundation for Science and Technology (FCT) through the project PEst-C/MAR/LA0015/2011. During the manuscript preparation, partial support was provided by national funds from FCT, within the Strategic Funding UID/Multi/04423/2013, and by ERDF, within the PT2020 programme. I.B. was supported by FCT through the Programa Ciência 2008Fundo Social Europeu and the BGCT/MAR/LA0015/2014/Science Management 002/2014 Grant.

\section{Publisher's Note}

Springer Nature remains neutral with regard to jurisdictional claims in published maps and institutional affiliations.

Received: 4 May 2017 Accepted: 4 October 2017

Published online: 17 October 2017

\section{References}

1. Wiens JA, Stenseth NC, Van Horne B, Ims RA. Ecological mechanisms and landscape ecology. Oikos. 1993;66:369-80.

2. Benedetti-Cecchi L. Variability in abundance of algae and invertebrates at different spatial scales on rocky sea shores. Mar Ecol Prog Ser. 2001;215:79-92.

3. Fraschetti S, Terlizzi A, Benedetti-Cecchi L. Patterns of distribution of rocky marine assemblages: evidence of relevant scales of variation. Mar Ecol Prog Ser. 2005;296:13-29.

4. Terlizzi A, Anderson MJ, Fraschetti S, Benedetti-Cecchi L. Scales of spatial variation in Mediterranean subtidal sessile assemblages at different depths. Mar Ecol Prog Ser. 2007;332:25-39.

5. Levin SA. The problem of pattern and scale in ecology. Ecology. 1992:73:1943-67.

6. Underwood AJ, Chapman MG. Scales of spatial patterns of distribution of intertidal invertebrates. Oecologia. 1996;107:212-24.

7. Bishop M, Underwood AJ, Archambault P. Sewage and environmental impacts on rocky shores: necessity of identifying relevant spatial scales. Mar Ecol Prog Ser. 2002;236:121-8.

8. Benedetti-Cecchi L, Bertocci I, Micheli F, Maggi E, Fosella T, Vaselli S. Implications of spatial heterogeneity for management of marine protected areas (MPAs): examples from assemblages of rocky coasts in the Northwest Mediterranean. Mar Environ Res. 2003;55:429-58.

9. Botsford LW, Micheli F, Hastings A. Principles for the design of marine reserves. Ecol Appl. 2003;13:S25-31.

10. Fraschetti S, Terlizzi A, Bussotti S, Guarnieri G, D'Ambrosio P, Boero F. Conservation of Mediterranean seascapes: analyses of existing protection schemes. Mar Environ Res. 2005;59:309-32.

11. Connolly RM, Roughgarden J. A latitudinal gradient in Northeast Pacific intertidal community structure: evidence for an oceanographically based synthesis of marine community theory. Am Nat. 1998;151:311-26.

12. Broitman BR, Navarrete SA, Smith F, Gaines SD. Geographic variation of southeastern Pacific intertidal communities. Mar Ecol Prog Ser. 2001;224:21-34

13. Floeter SR, Rocha LA, Robertson DR, Joyeux JC, Smith-Vaniz WF, Wirtz P, Edwards AJ, Barreiros JP, Ferreira CEL, Gasparini JL, Brito A, Falcón JM, Bowen BW, Bernardi G. Atlantic reef fish biogeography and evolution. J Biogeogr. 2008;35:22-47.
14. Kulbicki M, Parravicini V, Bellwood DR, Arias-Gonzàlez E, Chabanet $P$, Floeter SR, Friedlander A, McPherson J, Myers RE, Vigliola L, Mouillot D. Global biogeography of reef fishes: a hierarchical quantitative delineation of regions. PLoS ONE. 2013;8:e81847.

15. Kelaher BP, Chapman MG, Underwood AJ. Spatial patterns of diverse macrofaunal assemblages in coralline turf and their associations with environmental variables. J Mar Biol Assoc UK. 2001;81:917-30.

16. Bertocci I, Dominguez R, Freitas C, Sousa-Pinto I. Patterns of variation of intertidal species of commercial interest in the Parque Litoral Norte (North Portugal) MPA: comparison with three reference shores. Mar Environ Res. 2012;77:60-70.

17. Horne JK, Schneider DC. Spatial variance in ecology. Oikos. 1995;74:18-26.

18. Bertness MD, Bruno JF, Silliman BR, Stachowicz JJ. Marine community ecology and conservation. Sunderland: Sinauer Associates; 2014.

19. Guidetti P, Bianchi CN, Chiantore M, Schiaparelli S, Morri C, CattaneoVietti R. Living on the rocks: substrate mineralogy and the structure of subtidal rocky substrate communities in the Mediterranean Sea. Mar Ecol Prog Ser. 2004;274:57-68

20. Toohey BD, Kendrick GA. Canopy-understorey relationships are mediated by reef topography in Ecklonia radiata kelp beds. Eur J Phycol. 2008;43:133-42.

21. Schroeter SC, Reed DC, Raimondi PT. Effects of reef physical structure on development of benthic reef community: a large-scale artificial reef experiment. Mar Ecol Prog Ser. 2015;540:43-55.

22. Teixeira-Neves TP, Neves LM, Araújo FG. Hierarchizing biological, physical and anthropogenic factors influencing the structure of fish assemblages along tropical rocky shores in Brazil. Environ Biol Fishes. 2015:98:1645-57.

23. Connell JH, Keough MJ. Disturbance and patch dynamics of subtidal marine animals on hard substrata. In: Pickett STA, White PS, editors. The ecology of natural disturbance and patch dynamics. Orlando: Academic Press; 1985. p. 125-47.

24. Connell SD. Urban structures as marine habitats: an experimental comparison of the composition and abundance of subtidal epibiota among pilings, pontoons, and rocky reefs. Mar Environ Res. 2001;52:115-25.

25. Miller RJ, Etter RJ. Shading facilitates sessile invertebrate dominance in the rocky subtidal Gulf of Maine. Ecology. 2008;89:452-62.

26. Wernberg T, Connell SD. Physical disturbance and subtidal habitat structure on open rocky coasts: effects of wave exposure, extent and intensity. J Sea Res. 2008;59:237-48.

27. Kritzer JP, Sale PF. Marine metapopulations. Burlington: Elsevier Academic Press; 2006

28. Watson JR, Mitarai S, Siegel DA, Caselle J, Dong C, McWilliams JC. Realized and potential larval connectivity in the Southern California Bight. Mar Ecol Prog Ser. 2012:401:31-48.

29. Connell SD, Kingsford MJ. Spatial, temporal and habitat-related variation in the abundance of large predatory fish at One Tree Reef. Australia. Coral Reefs. 1998:17:49-57.

30. Anderson MJ, Millar RB. Spatial variation and effects of habitat on temperate reef fish assemblages in northeastern New Zealand. J Exp Mar Biol Ecol. 2004;305:191-221.

31. García-Charton JA, Pérez-Ruzafa A, Sánchez-Jerez P, Bayle-Sempere JT, Reñones O, Moreno D. Multi-scale spatial heterogeneity, habitat structure, and the effect of marine reserves on western Mediterranean rocky reef fish assemblages. Mar Biol. 2004;144:161-82.

32. Malcolm HA, Gladstone W, Lindfield S, Wraith J, Lynch TP. Spatial and temporal variation in reef fish assemblages of marine parks in New South Wales, Australia — baited video observations. Mar Ecol Prog Ser. 2007:350:277-90

33. Tuya F, Cacabelos E, Duarte P, Jacinto D, Castro J, Silva T, Bertocci I, Franco J, Arenas F, Coca J, Wernberg T. Patterns of landscape and assemblage structure along a latitudinal gradient in ocean climate. Mar Ecol Prog Ser. 2012:466:9-19.

34. Leathwick JR, Elith J, Francis MP, Hastie T, Taylor P. Variation in demersal fish species richness in the oceans surrounding New Zealand: an analysis using boosted regression trees. Mar Ecol Prog Ser. 2006;321:267-81.

35. Wellenreuther M, Syms C, Clements KD. Consistent spatial patterns across biogeographic gradients in temperate reef fishes. Ecography. 2008:31:84-94. 
36. Tuya F, Wernberg T, Thomsen MS. Testing the 'abundant centre' hypothesis on endemic reef fishes in south-western Australia. Mar Ecol Prog Ser. 2008;372:225-30

37. Newman SJ, Williams DM. Spatial and temporal variation in assemblages of Lutjanidae, Lethrinidae and associated fish species among mid-continental shelf reefs in the central Great Barrier Reef. Mar Freshw Res. 1996:52:843-51.

38. Friedlander AM, Parrish JD. Temporal dynamics of fish communities on an exposed shoreline in Hawaii. Environ Biol Fishes. 1998;53:1-18.

39. Jones GP, Syms C. Distribution, habitat structure and the ecology of fishes on coral reefs. Aust J Ecol. 1998:23:286-97.

40. Nash KL, Abesamis RA, Graham NAJ, McClure EC, Moland E. Drivers of herbivory on coral reefs: species, habitat and management effects. Mar Ecol Prog Ser. 2016;554:129-40.

41. Richardson LE, Graham NAJ, Pratchett MS, Hoey AS. Structural complexity mediates functional structure of reef fish assemblages among coral habitats. Environ Biol Fishes. 2017;100:193-207.

42. Willis TJ, Anderson MJ. Structure of cryptic reef fish assemblages: relationships with habitat characteristics and predator density. Mar Ecol Prog Ser. 2003;257:209-21.

43. Ordines F, Moranta J, Palmer M, Lerycke A, Suau A, Morales-Nin B, Grau AM. Variations in a shallow rocky reef fish community at different spatial scales in the western Mediterranean Sea. Mar Ecol Prog Ser. 2005:304:221-33.

44. Tuya F, Wernberg T, Thomsen MS. Habitat structure affect abundances of labrid fishes across temperate reefs in south-western Australia. Environ Biol Fishes. 2009:86:311-9.

45. Wedding L, Yoklavich MM. Habitat-based predictive mapping of rockfish density and biomass off the central California coast. Mar Ecol Prog Ser. 2015;540:235-50.

46. Connell SD, Irving A. Integrating ecology with biogeography using landscape characteristics: a case study of subtidal habitat across continental Australia. J Biogeogr. 2008;35:1608-21.

47. Bertocci I, Araújo R, Oliveira P, Sousa-Pinto I. Review: potential effects of kelp species on local fisheries. J Appl Ecol. 2015;52:1216-26.

48. Guidetti P. Marine reserves reestablish lost predatory interactions and cause changes in rocky reefs. Ecol Appl. 2006;16:963-76.

49. Clemente S, Hernandez JC, Brito A. Evidence of the top-down role of predators in structuring sublittoral rocky-reef communities in a Marine protected area and nearby areas of the Canary Islands. ICES J Mar Sci. 2009;66:64-71.

50. Santos LN, Brotto DS, Zalmon IR. Fish responses to increasing distance from artificial reefs on the Southeastern Brazilian Coast. J Exp Mar Biol Ecol. 2010;386:54-60.

51. García-Charton JA, Pérez-Ruzafa A. Ecological heterogeneity and the evaluation of the effects of marine reserves. Fish Res. 1999:42:1-20.

52. Russ $G$. Yet another review of marine reserves as reef fishery management tools. In: Sale PF, editor. Coral reef fishes: dynamics and diversity in a complex ecosystem. New York: Academic Press; 2002. p. 421-43.

53. García-Charton JA, Williams I, Pérez-Ruzafa A, Milazzo M, Chemello R, Marcos C, Kitsos M-S, Koukouras A, Riggio S. Evaluating the ecological effects of Mediterranean marine reserves: habitat, scale and the natural variability of ecosystems. Environ Conserv. 2000;27:159-78.

54. Anderson AB, Bonaldo RM, Barneche DR, Hackradt CW, Félix- Hackradt FC, García-Charton JA, Floeter SR. Recovery of grouper assemblages indicates effectiveness of a marine protected area in Brazil. Mar Ecol Prog Ser. 2014;514:207-15.

55. Boaventura D, Ré P, Fonseca LC, Hawkins SJ. Intertidal rocky shore communities of the continental Portuguese coast: analysis of distribution patterns. Mar Ecol. 2002;23:69-90.

56. Lima FP, Queiroz N, Ribeiro PA, Hawkins SJ, Santos AM. Geographic expansion of a marine gastropod, Patella rustica Linnaeus, 1758, and its relation with unusual climatic events. J Biogeogr. 2006;33:812-22.

57. Lima FP, Ribeiro PA, Queiroz N, Hawkins SJ, Santos AM. Do distributional shifts of northern and southern species of algae match the warming pattern? Glob Change Biol. 2007:13:2592-604.

58. Pereira SG, Lima FP, Queiroz NC, Ribeiro PA, Santos AM. Biogeographic patterns of intertidal macroinvertebrates and their association with macroalgae distribution along the Portuguese rocky coast. Hydrobiologia. 2006;555:185-92.
59. Assis J, Tavares D, Tavares J, Cunha A, Alberto F, Serrão EA. Findkelp, a GIS-based community participation project to assess Portuguese kelp conservation status. J Coast Res. 2009;56:1469-73.

60. Franco JN, Wernberg T, Bertocci I, Duarte P, Jacinto D, Rodrigues NV, Tuya F. Herbivory drives kelp recruits into 'hiding' under warm ocean climate. Mar Ecol Prog Ser. 2015;536:1-9.

61. Froese R, Pauly D. FishBase; 2015. www.fishbase.org. Accessed 24 Feb 2017.

62. Magurran AE, Henderson PA. How selection structures species abundance distributions. Proc R Soc B. 2012;279:3722-6.

63. Pinault M, Loiseau N, Chabanet P, Durville P, Magalon H, Quod JP, Galzin R. Marine fish communities in shallow volcanic habitats. J Fish Biol. 2013;82:1821-47.

64. Kinlan BP, Gaines SD, Lester SE. Propagule dispersal and the scales of marine community process. Div Distrib. 2005;11:139-48.

65. Root RB. The niche exploitation pattern of the blue-grey gnatcatcher. Ecol Monogr. 1967;37:317-50.

66. Southwood TRE, Lecture The Croonian. Natural communities: structure and dynamics. Phil Trans R Soc Lond B. 1995;1996(351):1113-29.

67. Hamilton WD. Geometry for the selfish herd. J Theor Biol. 1971;31:295-311.

68. Krause J, Ruxton GD. Living in groups. Oxford: Oxford University Press; 2002.

69. Henderson PA, Magurran AE. Linking species abundance distributions in numerical abundance and biomass through simple assumptions about community structure. Proc R Soc B. 2010;277:1561-70.

70. Harmelin-Vivien ML, Harmelin JG, Chauvet C, Duval C, Galzin R, Lejeune P, Barnabé G, Blanc F, Chevalier R, Duclerc J, Lasserre G. Evaluation visuelle des peuplements et populations de poissons: méthodes et problemes. Rev Ecol. 1985;40:467-539.

71. Tuya F, Wernberg T, Thomsen MS. The relative influence of local to regional drivers of variation in reef fishes. J Fish Biol. 2011;79:217-34.

72. Costa M. A wind driven wave climatology of the Portuguese coast. Report PO-Waves 6/94. Lisbon: Instituto Hidrográfico, Laboratório Nacional Engenharia Civil; 1994.

73. Lemos RT, Pires HE. The upwelling regime off the west Portuguese coast, 1941-2000. Int J Climatol. 2004;24:511-24.

74. Anderson MJ. A new method for non-parametric multivariate analysis of variance. Austral Ecol. 2001;26:32-46.

75. Winer BJ, Brown DR, Michels KM. Statistical principles in experimental design. New York: McGraw-Hill; 1991.

76. Underwood AJ. Experiments in ecology. Their logical design and interpretation using analysis of variance. Cambridge: Cambridge University Press; 1997.

77. Searle SR, Casella G, McCulloch CE. Variance components. New York: Wiley; 1992.

78. Terlizzi A, Benedetti-Cecchi L, Bevilacqua S, Fraschetti S, Guidetti P, Anderson MJ. Multivariate and univariate asymmetrical analyses in environmental impact assessments: a case study of Mediterranean subtidal sessile assemblages. Mar Ecol Prog Ser. 2005;289:27-42.

79. McArdle $\mathrm{BH}$, Anderson MJ. Fitting multivariate models to community data: a comment on distance-based redundancy analysis. Ecology. 2001;82:290-7.

80. Burnham KP, Anderson DR. Model selection and multimodel inference. New York: Springer; 2002.

81. Burnham KP, Anderson DR. Multimodel inference: understanding AIC and BIC in model selection. Sociol Methods Res. 2004:33:261-304

82. Wagenmakers E-J, Farrell S. AIC model selection using Akaike weights. Psychon Bull Rev. 2004;11:192-6.

83. Jones GP. Ecology of rocky reef fish of northeastern New Zealand: 50 years on. N Z J Mar Freshw Res. 2013;47:334-59.

84. Konar B, Edwards M, Efird T. Local habitat and regional oceanographic influence on fish distribution patterns in the diminishing kelp forests across the Aleutian Archipelago. Environ Biol Fishes. 2015;98:1935-51.

85. Hernández-Landa RC, Acosta-González G, Núñez-Lara E, Arias-González E. Spatial distribution of surgeonfish and parrot fish in the north sector of the Mesoamerican Barrier Reef System. Mar Ecol. 2015;36:432-46.

86. García-Charton JA, Pérez-Ruzafa A. Correlation between habitat structure and rocky reef fish assemblages in SW Mediterranean. PSZNI Mar Ecol. 1998;19:111-28. 
87. Zeller DC. Home range and activity patterns of the coral trout Plectropomus leopardus (Serranidae). Mar Ecol Prog Ser. 1997;154:65-77.

88. Jones KMM. Home range areas and activity centres in six species of Caribbean wrasses (Labridae). J Fish Biol. 2005;66:150-66.

89. Welsh JQ, Goatley CHR, Bellwood DR. The ontogeny of home ranges: evidence from coral reef fishes. Proc R Soc B. 2013;280:2013-66.

90. Larson RJ. Territorial behavior of the black and yellow rockfish and gopher rockfish (Scorpaenidae, Sebastes). Mar Biol. 1980;58:111-22.

91. Tolimieri N, Andrews K, Williams G, Katz S, Levin PS. Home range size and patterns of space use by lingcod, copper rockfish and quillback rockfish in relation to diel and tidal cycles. Mar Ecol Prog Ser. 2009;380:229-43.

92. Freiwald J. Movement of adult temperate reef fishes off the west coast of North America. Can J Fish Aquat Sci. 2012;69:1362-74.

93. Tolimieri N. Effects of microhabitat characteristics on the settlement and recruitment of a coral reef fish at two spatial scales. Oecologia. 1995;102:52-63.

94. Connell SD, Jones GP. The influence of habitat complexity on postrecruitment processes in a temperate reef fish population. J Exp Mar Biol Ecol. 1991;151:271-94.

95. Depczynski M, Bellwood DR. Wave energy and spatial variability in community structure of small cryptic coral reef fishes. Mar Ecol Prog Ser. 2005;303:283-93.

96. Choat JH, Ayling AM. The relationship between habitat structure and fish faunas on New Zealand reefs. J Exp Mar Biol Ecol. 1987;1 10:257-84.

97. Wellenreuther M, Connell SD. Response of predators to prey abundance: separating the effects of prey density and patch size. J Exp Mar Biol Ecol. 2002;273:61-71.

98. Levin PS. Small-scale variation in a temperate fish: the roles of macrophytes and food supply. Environ Biol Fishes. 1994;26:29-37.

99. Micheli F, Benedetti-Cecchi L, Gambaccini S, Bertocci I, Borsini C, Osio GC, Romano F. Cascading human impacts, marine protected areas, and the structure of Mediterranean reef assemblages. Ecol Monogr. 2005;75:81-102.
100. Quayle VA, Righton D, Hetherington S, Pickett G. Observations of the behaviour of European sea bass (Dicentrarchus labrax) in the North Sea. In: Nielsen JL, Arrizabalaga H, editors. Tagging and tracking of marine animals with electronic devices. Reviews: Methods and technologies in fish biology and fisheries, vol 9. Dordrecht: Springer; 2009. p. 103-19.

101. Morton JK, Gladstone W. Changes in rocky reef fish assemblages throughout an estuary with a restricted inlet. Hydrobiologia. 2014;724:235-53.

102. Tuya F, Ortega-Borges L, Sanchez-Jerez P, Haroun RJ. Effect of fishing pressure on the spatio-temporal variability of the parrotfish, Sparisoma cretense (Pisces: Scaridae), across the Canarian Archipelago (eastern Atlantic). Fish Res. 2006;77:24-33.

103. Thompson AA, Mapstone BD. Observer effects and training in underwater visual surveys of reef fishes. Mar Ecol Prog Ser. 1997;154:53-63.

104. Willis TJ, Badalamenti F, Milazzo M. Diel variability in counts of reef fishes and its implications for monitoring. J Exp Mar Biol Ecol. 2006;2006(33):108-20.

105. Leitão F, Baptista V, Zeller D, Erzini K. Reconstructed catches and trends for mainland Portugal fisheries between 1938 and 2009: implications for sustainability, domestic fish supply and imports. Fish Res. 2014;155:33-50

106. Shester GC, Micheli F. Conservation challenges for small-scale fisheries: bycatch and habitat impacts of traps and gillnets. Biol Conserv. 2011;144:1673-81.

107. Diamond JM. The island dilemma: lessons of modern biogeographic studies for the design of natural reserves. Biol Conserv. 1975;7:129-46.

108. Claudet J, Osenberg CW, Benedetti-Cecchi L, Domenici P, García-Charton J-A, Pérez-Ruzafa Á, Badalamenti F, Bayle-Sempere J, Brito A, Bulleri F, Culioli J-M, Dimech M, Falcón JM, Guala I, Milazzo M, Sánchez-Meca J, Somerfield PJ, Stobart B, Vandeperre F, Valle C, Planes S. Marine reserves: size and age do matter. Ecol Lett. 2008;11:481-9.

109. Hattori $H$, Shibuno T. The effect of patch reef size on fish species richness in a shallow coral reef shore zone where territorial herbivores are abundant. Ecol Res. 2010;25:457-68.

\section{Submit your next manuscript to BioMed Central and we will help you at every step:}

- We accept pre-submission inquiries

- Our selector tool helps you to find the most relevant journal

- We provide round the clock customer support

- Convenient online submission

- Thorough peer review

- Inclusion in PubMed and all major indexing services

- Maximum visibility for your research

Submit your manuscript at www.biomedcentral.com/submit
() Biomed Central 